\title{
Dental Age Estimation in Southern Turkish Children: Comparison of Demirjian and Willems Methods
}

\author{
Halenur Altan, ${ }^{1}$ Ahmet Altan, ${ }^{2, *}$ and Ozlem Akinci Sozer ${ }^{3}$ \\ ${ }^{1}$ DDS, Ph.D, Assistant Professor, Department of Pediatric Dentistry, Faculty of Dentistry, Gaziosmanpasa University, Tokat, Turkey \\ ${ }^{2}$ DDS, Ph.D, Assistant Professor, Department of Oral and Maxillofacial Surgery, Faculty of Dentistry, Gaziosmanpasa University, Tokat, Turkey \\ ${ }^{3}$ DDS, Ph.D, Assistant Professor, Department of Orthodontics, Faculty of Dentistry, Mustafa Kemal University, Hatay, Turkey \\ "Corresponding author: Dr. Ahmet Altan, Gaziosmanpasa University, Faculty of Dentistry, Ali Sevki Erek Yerleskesi, 60100 Tokat, Turkey. Tel: +90-5057013189, E-mail: \\ dt.ahmetaltan@gmail.com
}

Received 2017 April 12; Revised 2017 September 04; Accepted 2017 September 24.

\begin{abstract}
Background: Age-related legal problems are particularly common in underdeveloped parts of Turkey. Age determination is important in terms of both laws and penalties in the legal process.

Objectives: The aim of the present study was to compare the validity of the Demirjian and Willems methods in southern Turkish children.

Methods: In this retrospective study, panoramic radiographs of 745 southern Turkish children (382 boys and 363 girls) aged between 4 and 15.99 years were examined by one investigator. According to Demirjian and Willems method, the mean difference between chronological and dental age was calculated for each sex and age group. The Wilcoxon test was used to compare all data. Statistical analysis was performed to test the validity of Demirjian and Willems methods by comparing the mean estimated and chronological age.

Results: The Demirjian's method overestimated age with a mean accuracy of 0.832 in females and by 0.923 in males, while Willems method overestimated it by 0.202 in females and 0.434 in males.

Conclusions: The dental age estimation by Willems method was found to be more accurate than Demirjian method in contemporary Turkish pediatric population.
\end{abstract}

Keywords: Age Estimation, Chronologic Age, Dental Age, Demirjian’s Method, Willems' Method, Forensic Odontology

\section{Background}

Age determination is important in terms of both laws and penalties in the legal process (1). It may be used to identify individuals particularly in cases in which identification can not be performed. Age determination may also be needed in cases of suspicious death, baby corpses, and individuals lacking mental health. Age determination is especially important for individuals living in developing socities where the records of citizens are not regularly kept.

In recent years, the war in Syria and influx of refugees into Turkey (especially southern border region) has caused an increase in the number of physical abuse and neglect cases. Child abuse and neglect result in an increase in the number of unidentified infant and child deaths.

Dental tissues are less affected by endocrine disorders or by dietary differences compared to other tissues in the body $(2,3)$. If one of the teeth is fully mineralized, its form is stable, and developmental and retroactive variations in this status relate to chronological age (4). Hu- man growth is a complex process that is mainly genetically but also environmentally determined. The body growth due to the proliferation of tissues is regulated by several environmental factors. These factors can be affected adversely by increasing consumption of processed foods, additives, toxins, environmental pollution, insufficient sunlight exposure, and inactivity (2). Adversely affected body balance and chronic diseases (diabetes, thyroid disorders, and heart disorders) that delay dental growth have been observed among very young children.

Methods involving teeth for age estimation among children were developed by Nolla in 1960 (5), Moorrees in 1963 (6), Haavikko in 1970 (7), and Demirjian in 1973 (8). These methods are all based on morphological evaluation of dental growth. The most frequently used method to determine age according to dental growth is Demirjian's $(8,9)$. Dental growth in this method is described in eight stages from $\mathrm{A}$ to $\mathrm{H}$ and evaluations are made on the left lower jaw on seven molar teeth (except the wisdom teeth). 
A total score out of 100 for dental growth is determined by checking the respective values of the table at the growth stage of each tooth, and dental age can be estimated based on the standards that have been created. As the estimations using Demirjian's method began to give overestimated results than just the chronological age, Willems et al. revised the method (10).

The aim of the present study is to compare the validity of the Demirjian and Willems methods, which are used in dental age estimation, in healthy Turkish children living in the south of Turkey.

\section{Methods}

In this retrospective study, digital panoramic radiographs of 745 southern Turkish children were collected from Faculty of Dentistry, Mustafa Kemal University in Hatay, Turkey. It consisted of 363 girls and 382 boys of 4 to 15.99 years old in both sexes (Table 1). The panoramic radiographs were selected from patients who underwent radiological examination during the dental treatment period. All radiographs were obtained using PantOs DG XP ceph (Blue-x Imaging S.r.I., Assago, Italy).

Table 1. Distribution of Age and Gender in Study Population

\begin{tabular}{lccc}
\hline Age & Female & Male & Total \\
\hline $\mathbf{4}-\mathbf{4 , 9}$ & 8 & 12 & 20 \\
\hline $\mathbf{5}-\mathbf{5 , 9}$ & 21 & 27 & 48 \\
\hline $\mathbf{6}-\mathbf{6 , 9}$ & 24 & 26 & 50 \\
\hline $\mathbf{7}-\mathbf{7 , 9}$ & 28 & 31 & 59 \\
\hline $\mathbf{8}-\mathbf{8 , 9}$ & 34 & 28 & 62 \\
\hline $\mathbf{9}-\mathbf{9 , 9}$ & 32 & 39 & 71 \\
\hline $\mathbf{1 0}-\mathbf{1 0 , 9}$ & 40 & 42 & 82 \\
\hline $\mathbf{1 1}-\mathbf{1 1 , 9}$ & 45 & 48 & 93 \\
\hline $\mathbf{1 2}-\mathbf{1 2 , 9}$ & 44 & 49 & 93 \\
\hline $\mathbf{1 3}-\mathbf{1 3 , 9}$ & 28 & 31 & 59 \\
\hline $\mathbf{1 4}-\mathbf{1 4 , 9}$ & 25 & 26 & 51 \\
\hline $\mathbf{1 5}-\mathbf{1 5 , 9}$ & 34 & 23 & 57 \\
\hline Total & 363 & 382 & 745 \\
\hline
\end{tabular}

Participants were selected from Turkish citizens born in Hatay, Turkey. Only digital panoramic radiographs of adequate quality were selected. The patients with congenital anomalies, previous orthodontic treatment, history of dental trauma, hypodontia of permanent teeth except 3rd molars, deformities, pathological conditions (odontoma, cysts etc.) were excluded.
The chronological age of each subject was calculated by subtracting the date of the orthopantomographic examination from the date of birth after converting both to a decimal age. The panoramic radiographs were assessed in order to determine the developmental stages of the teeth according to the methods of Demirjian and Willems. The overall maturity score was then converted to a dental age by using these methods. The investigator did not know the chronologic age of subjects when assessing the radiographs. The differences between chronological and dental age were also analyzed to clarify the accuracy of the two methods.

To assess the repeatability of our analysis, 75 orthopantomographic radiographs (10\% from each age category) were randomly selected and reassessed by the same investigator three months after the first assessment. To evaluate intra-observer agreement, Cohen's Kappa test was applied.

\subsection{Statistical Analysis}

Statistical analysis was performed using statistical package for social sciences (SPSS) for Windows 21.0 software. Continuous variables for normality the KolmogorovSmirnov test was used. The test rejected the assumed normal distribution and nonparametric tests were required. The Wilcoxon test was used to compare all data according to gender and age groups. The Wilcoxon test was also used in evaluation of overestimation produced by Demirjian and Willems methods. In all analyses P-value of less than 0.05 was considered significant for all statistical data.

\section{Results}

After applying Demirjian method (Tables 2 and 3), the Kolmogorov-Smirnov test indicated an abnormal distribution. The Wilcoxon test showed no statistically significant difference between chronological age and dental age in females in the 9-9.99 and 15-15.99 age group, but a statistically significant difference was found in all other age groups $(P<0.05)$. Similarly, a statistically significant difference was found in all age groups among males $(\mathrm{P}<$ 0.05).

The Wilcoxon test applied after the Willems method showed no statistically significant difference between the chronological and dental ages in the 5-5.99, 6-6.99 and 99.99 age groups in females. But there was a statistically significant difference in all other age groups $(\mathrm{P}<0.05)$. Similarly, while no difference was observed among males in the 5-5.99, 12-12.99, 13-13.99 and 14-14.99 age groups, a statistically significant difference was observed in all other age groups $(\mathrm{P}<0.05)$ (Tables 2 and 3 ).

This study revealed that the dental age using Demirjian method was estimated by 0.832 in females and by 0.923 
Table 2. Comparison of Chronogical Age and Dental Age According to the Demirjian's and Willems' Methods Among Girls by Age Categories

\begin{tabular}{|c|c|c|c|c|c|c|c|c|c|c|}
\hline \multirow[t]{3}{*}{ Chronological Age Range } & \multicolumn{10}{|c|}{ Dental Age } \\
\hline & \multicolumn{5}{|c|}{ Demirjian's Method } & \multicolumn{5}{|c|}{ Willems' Method } \\
\hline & Mean Age & Minimum & Maximum & SD & PValue & Mean Age & Minimum & Maximum & SD & PValue \\
\hline $4.00-4.99$ & 5.275 & 4.40 & 6.70 & 0.757 & $0.012^{\mathrm{a}}$ & 4.555 & 4.34 & 5.00 & 0.235 & $0.012^{\mathrm{a}}$ \\
\hline $5.00-5.99$ & 6.267 & 4.80 & 7.10 & 0.635 & $0.000^{\mathrm{a}}$ & 5.130 & 4.15 & 5.84 & 0.489 & 0.384 \\
\hline $6.00-6.99$ & 7.096 & 6.60 & 7.40 & 0.240 & $0.000^{\mathrm{a}}$ & 6.047 & 5.37 & 6.87 & 0.419 & 0.547 \\
\hline $7.00-7.99$ & 7,703 & 7,10 & 8,20 & 0,303 & $0,000^{a}$ & 7,422 & 6,31 & 8.15 & 0.529 & $0.001^{\mathrm{a}}$ \\
\hline $8.00-8.99$ & 8.626 & 8.00 & 10.10 & 0.601 & $0.000^{\mathrm{a}}$ & 8.322 & 7.83 & 9.64 & 0.467 & $0.006^{\mathrm{a}}$ \\
\hline $9.00-9.99$ & 9.240 & 5.60 & 11.60 & 1.024 & 0.067 & 8.841 & 7.83 & 10.67 & 0.685 & 0.080 \\
\hline $10.00-10.99$ & 11.222 & 9.10 & 13.70 & 1.010 & $0.000^{\mathrm{a}}$ & 10.600 & 9.02 & 12.88 & 0.883 & $0.000^{\mathrm{a}}$ \\
\hline $11.00-11.99$ & 12.076 & 9.60 & 15.00 & 0.759 & $0.000^{\mathrm{a}}$ & 11.512 & 9.71 & 13.84 & 0.675 & $0.000^{\mathrm{a}}$ \\
\hline $12.00-12.99$ & 12.995 & 9.10 & 16,00 & 1,159 & $0,000^{\mathrm{a}}$ & 12,303 & 9,71 & 15,79 & 1,032 & $0,011^{\mathrm{a}}$ \\
\hline $13.00-13.99$ & 14,107 & 12,30 & 16,00 & 0,922 & $0,000^{a}$ & 13,395 & 11,99 & 15,79 & 0,978 & $0,025^{\mathrm{a}}$ \\
\hline $14.00-14.99$ & 14,656 & 13,10 & 16,00 & 0,720 & $0,000^{\mathrm{a}}$ & 13,724 & 11,49 & 15,79 & 0,866 & $0,001^{\mathrm{a}}$ \\
\hline $15.00-15.99$ & 15,053 & 13,70 & 16,00 & 0,745 & 0,639 & 14,500 & 12.88 & 15.79 & 1.009 & $0.000^{\mathrm{a}}$ \\
\hline All & 10.980 & 4.40 & 16.00 & 3.029 & $0.000^{\mathrm{a}}$ & 10.351 & 4.15 & 15.79 & 3.024 & $0.000^{\mathrm{a}}$ \\
\hline
\end{tabular}

${ }^{\mathrm{a}}$ Statistically significant difference.

Table 3. Comparison of Chronogical Age and Dental Age According to the Demirjian's and Willems' Methods Among Boys by Age Categories

\begin{tabular}{|c|c|c|c|c|c|c|c|c|c|c|}
\hline \multirow[t]{3}{*}{ Chronological Age Range } & \multicolumn{10}{|c|}{ Dental Age } \\
\hline & \multicolumn{5}{|c|}{ Demirjian's Method } & \multicolumn{5}{|c|}{ Willems' Method } \\
\hline & Mean Age & Minimum & Maximum & SD & PValue & Mean Age & Minimum & Maximum & SD & PValue \\
\hline $4.00-4.99$ & 5.617 & 4.50 & 7,00 & 0,779 & $0,002^{\mathrm{a}}$ & 4,699 & 3.96 & 5.95 & 0.629 & $0.009^{\mathrm{a}}$ \\
\hline $5.00-5.99$ & 6.396 & 5.60 & 6.70 & 0.257 & $0.000^{\mathrm{a}}$ & 5.179 & 4.41 & 5.74 & 0.372 & 0.109 \\
\hline $6.00-6.99$ & 7.192 & 6.20 & 8.00 & 0.401 & $0.000^{\mathrm{a}}$ & 6.675 & 5.13 & 7.96 & 0.630 & $0.000^{\mathrm{a}}$ \\
\hline $7.00-7.99$ & 8.029 & 7.00 & 8.50 & 0.400 & $0.000^{\mathrm{a}}$ & 7.828 & 6.21 & 8.42 & 0.574 & $0.000^{\mathrm{a}}$ \\
\hline $8.00-8.99$ & 8.875 & 7.90 & 10.70 & 0.681 & $0.000^{\mathrm{a}}$ & 8.770 & 7.91 & 10.54 & 0.651 & $0.000^{\mathrm{a}}$ \\
\hline $9.00-9.99$ & 9.623 & 8.50 & 12.30 & 1.111 & $0.008^{\mathrm{a}}$ & 9.498 & 8.42 & 11.95 & 0.919 & $0.003^{\mathrm{a}}$ \\
\hline $10.00-10.99$ & 10.857 & 8.80 & 12.80 & 0.927 & $0.000^{\mathrm{a}}$ & 10.497 & 9.09 & 12.38 & 0.777 & $0.001^{\mathrm{a}}$ \\
\hline $11.00-11.99$ & 11.891 & 8.70 & 14.00 & 1.042 & $0.000^{\mathrm{a}}$ & 11.495 & 8.62 & 13.11 & 0.959 & $0.002^{\mathrm{a}}$ \\
\hline $12.00-12.99$ & 12.871 & 9.60 & 15.80 & 1.286 & $0.000^{\mathrm{a}}$ & 12.312 & 9.60 & 14.34 & 0.973 & 0.356 \\
\hline $13.00-13.99$ & 13.745 & 12.50 & 15.80 & 0.987 & $0.000^{\mathrm{a}}$ & 13.040 & 11.90 & 14.34 & 0.741 & 0.798 \\
\hline $14.00-14.99$ & 14.804 & 12.50 & 16.00 & 1.234 & $0.002^{\mathrm{a}}$ & 14.015 & 11.90 & 16.03 & 1.245 & 0.451 \\
\hline $15.00-15.99$ & 15.80 & 14.40 & 16.00 & 0.451 & $0.000^{\mathrm{a}}$ & 15.303 & 13.59 & 16.03 & 0.947 & $0.042^{\mathrm{a}}$ \\
\hline All & 10.815 & 4.50 & 16.00 & 2.997 & $0.000^{\mathrm{a}}$ & 10.327 & 3.96 & 16.03 & 2.988 & $0.000^{\mathrm{a}}$ \\
\hline
\end{tabular}

${ }^{\mathrm{a}}$ Statistically significant difference.

in males more than chronological age, and using Willems method by 0.202 in females and by 0.434 in males. A comparative analysis was performed to identify the overestimation between the Demirjian and Willems methods and found no statistically significant difference in the 15-15.99 age groups among males. but a significant difference was observed in all other groups in females and males $(\mathrm{P}<$ 0.05). (Tables 4 and 5).

\section{Discussion}

Families who become homeless after migration or live as refugees are vulnerable to external threats in uncontrolled migration-receiving countries or cities. In addition, these areas may have families with severe economic problems, broken families, increasing the number of extramarital orphaned children, and child employment, which cause increase in the number of physical abuse and neglect cases. Therefore, age determination methods have become important to be indicative of actual development age to be able to manage the legal process properly. To find a more appropriate method for this, the validity of Demirjian (8) and Willems (11) methods were compared in children living in this region. The study found that the Willems method provided more accurate results.

The Demirjian's method is one of the most widely known and used methods (12). The original and revised 
Table 4. Comparison of Under/Overestimation Age According to the Demirjian's and Willems' Methods Among Girls by Age Categories

\begin{tabular}{|c|c|c|c|c|c|c|c|c|c|}
\hline \multirow[t]{3}{*}{ Chronological Age Range } & \multicolumn{8}{|c|}{ Age Under/Overestimation } & \multirow{3}{*}{$\begin{array}{c}\text { Demirjian's vs Willems' Method } \\
\text { PValue }\end{array}$} \\
\hline & \multicolumn{4}{|c|}{ Demirjian's Method } & \multicolumn{4}{|c|}{ Willems' Method } & \\
\hline & Mean Age & Minimum & Maximum & SD & Mean Age & Minimum & Maximum & SD & \\
\hline $4.00-4.99$ & 1.275 & 0.40 & 2,70 & 0,757 & 0,555 & 1.00 & 5.55 & 0.235 & $0.017^{\mathrm{a}}$ \\
\hline $5.00-5.99$ & 1.266 & -0.20 & 2.10 & 0.635 & 0.130 & -0.85 & 0.85 & 0.489 & $0.000^{\mathrm{a}}$ \\
\hline $6.00-6.99$ & 1.095 & 0.60 & 1.40 & 0.240 & 0.047 & -0.63 & 0.87 & 0.419 & $0.000^{\mathrm{a}}$ \\
\hline $7.00-7.99$ & 0.703 & 0.10 & 1.20 & 0.303 & 0.422 & -0.69 & 1.15 & 0.529 & $0.000^{\mathrm{a}}$ \\
\hline $8.00-8.99$ & 0.626 & 0.00 & 2.10 & 0.601 & 0.322 & -0.17 & 0.32 & 0.467 & $0.000^{\mathrm{a}}$ \\
\hline $9.00-9.99$ & -0.158 & -3.40 & 2.60 & 1.024 & $-0,158$ & $-1,17$ & 1,67 & 0,685 & $0,001^{a}$ \\
\hline $10.00-10.99$ & 1,222 & $-0,90$ & 3,70 & 1,010 & 0,600 & $-0,98$ & 2,88 & 0,883 & $0,000^{\mathrm{a}}$ \\
\hline $11.00-11.99$ & 1,075 & $-1,40$ & 4,00 & 0,759 & 0,512 & $-1,29$ & 2,84 & 0,675 & $0,000^{\mathrm{a}}$ \\
\hline $12.00-12.99$ & 0,995 & $-2,90$ & 4,00 & 1,158 & 0,303 & -2.29 & 3.79 & 1.032 & $0.000^{\mathrm{a}}$ \\
\hline $13.00-13.99$ & 1.107 & -0.70 & 3.00 & 0.922 & 0.395 & -1.01 & 2.79 & 0.978 & $0.000^{\mathrm{a}}$ \\
\hline $14.00-14.99$ & 0.656 & -0.90 & 2.00 & 0.720 & -0.276 & -2.51 & 1.79 & 0.866 & $0.000^{\mathrm{a}}$ \\
\hline $15.00-15.99$ & 0.052 & -1.30 & 1.00 & 0.745 & -0.499 & -2.12 & 0.79 & 1.009 & $0.000^{\mathrm{a}}$ \\
\hline All & 0.832 & -3.40 & 4.00 & 0.896 & 0.202 & -2.51 & 3.79 & 0.838 & $0.000^{\mathrm{a}}$ \\
\hline
\end{tabular}

${ }^{\mathrm{a}}$ Statistically significant difference.

Table 5. Comparison of Under/Overestimation Age According to the Demirjian's and Willems' Methods Among boys by Age Categories

\begin{tabular}{|c|c|c|c|c|c|c|c|c|c|}
\hline \multirow[t]{3}{*}{ Chronological Age Range } & \multicolumn{8}{|c|}{ Age Under/Overestimation } & \multirow{3}{*}{$\begin{array}{c}\text { Demirjian's vs Willem's Method } \\
\text { PValue }\end{array}$} \\
\hline & \multicolumn{4}{|c|}{ Demirjian's Method } & \multicolumn{4}{|c|}{ Willems' Method } & \\
\hline & Mean Age & Minimum & Maximum & SD & Mean Age & Minimum & Maximum & SD & \\
\hline $4.00-4.99$ & 1.616 & 0.50 & 3.00 & 0.777 & 0.699 & -0.04 & 1.95 & 0.629 & $0.002^{\mathrm{a}}$ \\
\hline $5.00-5.99$ & 1.396 & 0.60 & 1.70 & 0.257 & 0.179 & -0.59 & 0.74 & 0.372 & $0.000^{\mathrm{a}}$ \\
\hline $6.00-6.99$ & 1.192 & 0.20 & 2,00 & 0.401 & 0.675 & -0.87 & 1.96 & 0.630 & $0.000^{\mathrm{a}}$ \\
\hline $7.00-7.99$ & 1.029 & 0.00 & 1.50 & 0.400 & 0.828 & -0.79 & 1.42 & 0.574 & $0.000^{\mathrm{a}}$ \\
\hline $8.00-8.99$ & 0.875 & -0.09 & 2.70 & 0.681 & 0.770 & -0.09 & 2.54 & 0.651 & $0.035^{\mathrm{a}}$ \\
\hline $9.00-9.99$ & 0.623 & -0.50 & 3.30 & 1.111 & 0.498 & -0.58 & 2.95 & 0.919 & $0.042^{\mathrm{a}}$ \\
\hline $10.00-10.99$ & 0.857 & -1.20 & 2.80 & 0.927 & 0.497 & -0.91 & 2.38 & 0.777 & $0.000^{\mathrm{a}}$ \\
\hline $11.00-11.99$ & 0.891 & -2.30 & 3.00 & 1.042 & 0.495 & -2.38 & 2.11 & 0.959 & $0.000^{\mathrm{a}}$ \\
\hline $12.00-12.99$ & 0.871 & -2.40 & 3.80 & 1.286 & 0.312 & -2.40 & 2.34 & 0.973 & $0,000^{\mathrm{a}}$ \\
\hline $13.00-13.99$ & 0.745 & -0.50 & 2.80 & 0.987 & 0.040 & $-1,10$ & 1.34 & 0.741 & $0,000^{\mathrm{a}}$ \\
\hline $14.00-14.99$ & 0.803 & -1.50 & 2.00 & 1.234 & 0.015 & -2.10 & 2.03 & 1.245 & $0.000^{\mathrm{a}}$ \\
\hline $15.00-15.99$ & 0.800 & -0.60 & 1.00 & 0.451 & 0.303 & -1.41 & 1.03 & 0.947 & 0.301 \\
\hline All & 0.923 & -2.40 & 3.80 & 0.936 & 0.434 & -2.40 & 2.95 & 0.861 & $0.000^{\mathrm{a}}$ \\
\hline
\end{tabular}

${ }^{\mathrm{a}}$ Statistically significant difference.

form of this method has been applied and tested in different populations for years (13). The dental age estimations performed using the Demirjian method in Turkish children living in different geographical locations usually overestimated chronological age $(9,11,13,14)$. Willems et al. (10) published their revised maturity scores almost 25 years after Demirjian et al.'s study (8). In the 25-year interval, dental maturation has changed rapidly due to refined food, immobility, and decreased exposure to sunlight. Therefore, Willems et al.'s maturity scores more accurately reflect conditions of the present time than Demirjian's method does. In the current study, the overestimation of chronological age in different regions of Turkey was observed, but the Demirjian's method also overestimated the dental age estimation.

This study is the first to compare Demirjian's and Willems' method for age estimation in southern Turkish population. Willems method provided an accurate age in the $5-5.99,12-12.99,13-13.99,14-14.99$ age groups in males and in the 5 - 5.99, 6 - 6.99, 9 - 9.99 age groups in females in children living in the south of Turkey. The Demirjian's method was only valid in females in the 9-9.99 and 15-15.99 age groups. In Turkey, sexual abuse of children is observed in all age groups, it is most commonly seen between 4 - 8 years of age. The abuse ratio decreases with age in males (15) and there are more cases during puberty ( 9 - 18 years) 
than in other age groups in females.

In different populations, Almotairy and Pegelow (16) compared the chronological and dental age in healthy and non-syndromic Caucausian children with unilateral cleft lip and palate obtained byWillems and Demirjian methods. It was reported that Willems method had greater accuracy in estimating chronological age than Demirjian's method in both groups. Hegde et al. (17) tested applicability of four different age estimation methods in Indian children. It was reported that age estimated with Willems method was the most accurate followed by Demirjian's method. Similar to previous studies, in this current study, Willems method can be used to estimate the dental age of Southern Turkish children.

\subsection{Conclusions}

Childhood abuse and neglect have become universal problems and dental age estimation is a very important issue in determining child abuse and neglect cases. Child age is required in the implementation of penalties. This study is the first to compare Willems and Demirjian methods for age estimation in southern Turkish population. This study contributes to the literature because it provides an appropriate method to quickly and accurately determine the age of children who have suffered abuse and neglect.

\section{Acknowledgments}

The authors would like to thank Dr. Osman Kursat Onat for his statistical assistance.

\section{References}

1. Onat Altan H, Altan A, Bilgic F, Akinci Sozer O, Damlar I. The applicability of Willems' method for age estimation in southern Turkish children: A preliminary study. J Forensic Leg Med. 2016;38:24-7. doi: 10.1016/j.jflm.2015.11.015. [PubMed: 26698388].

2. Cameriere R, Flores-Mir C, Mauricio F, Ferrante L. Effects of nutrition on timing of mineralization in teeth in a Peruvian sample by the Cameriere and Demirjian methods. Ann Hum Biol. 2007;34(5):547-56. doi:10.1080/03014460701556296. [PubMed: 17786590].
3. Rai B, Anand SC. Tooth developments: an accuracy of age estimation of radiographic methods. World J Med Sci. 2006;1(2):130-2.

4. Martrille L, Ubelaker DH, Cattaneo C, Seguret F, Tremblay M, Baccino E. Comparison of four skeletal methods for the estimation of age at death on white and black adults. J Forensic Sci. 2007;52(2):302-7. doi: 10.1111/j.1556-4029.2006.00367.x. [PubMed: 17316225].

5. Nolla CM. The development of permanent teeth. University of Michigan; 1952.

6. Moorrees CF, Fanning EA, Hunt EJ. Formation and Resorption of Three Deciduous Teeth in Children. Am J Phys Anthropol. 1963;21:205-13. [PubMed: 14110696].

7. Haavikko K. The formation and the alveolar and clinical eruption of the permanent teeth. An orthopantomographic study. Suom Hammaslaak Toim. 1970;66(3):103-70. [PubMed: 4917152].

8. Demirjian A, Goldstein H, Tanner JM. A new system of dental age assessment. Hum Biol. 1973;45(2):211-27. [PubMed: 4714564].

9. Tunc ES, Koyuturk AE. Dental age assessment using Demirjian's method on northern Turkish children. Forensic Sci Int. 2008;175(1):236. doi:10.1016/j.forsciint.2007.04.228. [PubMed: 17560060].

10. Willems G, Van Olmen A, Spiessens B, Carels C. Dental age estimation in Belgian children: Demirjian's technique revisited. J Forensic Sci. 2001;46(4):893-5. [PubMed: 11451073].

11. Celikoglu M, Cantekin K, Ceylan I. Dental age assessment: the applicability of Demirjian method in eastern Turkish children.J Forensic Sci. 2011;56 Suppl 1:S220-2. doi: 10.111//j.1556-4029.2010.01598.x. [PubMed: 21198621].

12. Garamendi PM, Landa MI, Ballesteros J, Solano MA. Reliability of the methods applied to assess age minority in living subjects around 18 years old. A survey on a Moroccan origin population. Forensic Sci Int. 2005;154(1):3-12. doi: 10.1016/j.forsciint.2004.08.018. [PubMed: 16182943].

13. Celik S, Zeren C, Celikel A, Yengil E, Altan A. Applicability of the Demirjian method for dental assessment of southern Turkish children.J Forensic Leg Med. 2014;25:1-5. doi: 10.1016/j.jflm.2014.04.006. [PubMed: 24931852].

14. Altunsoy M, Nur BG, Akkemik O, Ok E, Evcil MS. Applicability of the Demirjian method for dental age estimation in western Turkish children. Acta Odontol Scand. 2015;73(2):121-5. doi: 10.3109/00016357.2014.956333. [PubMed: 25314122].

15. Kaplan SJ, Pelcovitz D, Labruna V. Child and adolescent abuse and neglect research: a review of the past 10 years. Part I: Physical and emotional abuse and neglect. J Am Acad Child Adolesc Psychiatry. 1999;38(10):1214-22. doi: 10.1097/00004583-199910000-00009. [PubMed: 10517053].

16. Almotairy N, Pegelow M. Dental age comparison in patients born with unilateral cleft lip and palate to a control sample using Demirjian and Willems methods. EurJ Orthod. 2017 doi: 10.1093/ejo/cjx031. [PubMed: 28472275].

17. Hegde S, Patodia A, Dixit U. A comparison of the validity of the Demirjian, Willems, Nolla and Haavikko methods in determination of chronological age of 5-15 year-old Indian children.J Forensic Leg Med. 2017;50:49-57. doi:10.1016/j.jflm.2017.07.007. [PubMed: 28708981]. 